\title{
Adoption of E-Voting System in Nigeria: A Conceptual Framework
}

\author{
Salimonu, R. \\ Ishaq \\ School of Computing \\ College of Arts and \\ Sciences \\ Universiti Utara \\ Malaysia, 06010, \\ Sintok, Malaysia.
}

\author{
Wan Rozaini Bt. \\ Sheik Osman \\ School of Computing \\ College of Arts and \\ Sciences \\ Universiti Utara \\ Malaysia, 06010, \\ Sintok, Malaysia.
}

\author{
Abdul Jaleel \\ Kehinde Shittu \\ School of Computing \\ College of Arts and \\ Sciences \\ Universiti Utara \\ Malaysia, 06010, \\ Sintok, Malaysia.
}

\author{
Jimoh, R.G. \\ Department of \\ Computer Science \\ Faculty of \\ Communication and \\ Information Sciences \\ University of Ilorin,
}

\begin{abstract}
Evidences have shown that it is only the electronic voting system that can deliver credible, fraud free elections in Nigeria. The delay in the implementation of this platform in Nigeria has nothing to do with the electorates with previous studies revealing the readiness of Nigerians to use and accept the electronic voting system. The major bottleneck has to do with the body entrusted with the responsibility of conducting election in the country i.e. Independent National Electoral Commission (INEC). This motivates the researcher to examine what can be done at this level to achieve successful implementation of this technology. In this paper, a conceptual framework for the study is presented integrating Diffusion of Innovation (DOI) model, Technology-Organization-

Environment (TOE) framework and Iacovou et al. constructs. The presented framework serves as the basis of this study.
\end{abstract}

\section{Keywords}

Electronic Voting, conceptual framework, DOI, TOE, Iacovou

\section{INTRODUCTION}

Integrating and combining constructs of two or more theoretical models have improved the understanding of a complex Information Technology (IT) or technological innovations compared with using one theoretical model for the same study ([22], [17], [14], [3]). This research, therefore integrate factors or constructs from [16], [20], [10], since this is the current trends in IT adoption studies, to develop a conceptual framework to study the adoption of E-voting systems within the organizational context. E-voting is central to E-democracy and E-participation initiatives of government. It involves the use of IT and electronic devices as a means of casting votes. Countries such as USA, Brazil, India, and Estonia, not only legislate its uses but have implemented it over the years ([21], [5]). In Nigeria, previous studies have shown the readiness and acceptance of citizens for the use of E-voting in the conduct of future elections ([9], [4], [12]). Yet, no study has identified the determinant factors that influence the organizational adoption of E-voting by an electoral management body such as the Independence National Electoral Commission of Nigeria (INEC). This research is aimed at developing a holistic understanding of IT adoption factors within the context of E-Voting Systems adoption from the perceptions of the managerial and operational staff of an electoral body (organization) by (1) integrating the key constructs of TOE, DOI, and Iacovou et al., through a new conceptual model- E-Voting System Adoption Model (EVSAM); and (2) testing the model in a setting of E-Voting System adoption within the organizational context.

\section{THEORETICAL MODELS FOR IT ADOPTION STUDY}

Among the theories been used in the organizational study of IT adoption includes: (1) Diffusion on Innovations (DOI) [16], (2) Technology-Organization-Environment (TOE) framework [20], (3) Iacovou et al. Model [10]. The following sections discuss these theories. The choice of these models is based on the fact that Independent Electoral Commission (INEC), Nigeria serves as the domain of this study having established the readiness of Nigerians (Voters) to use this technology.

\subsection{Diffusion of Innovation (DOI)}

The theory has a wider support in IT adoption research. It described the introduction of innovations as being communicated through particular channels over a period and within certain social system [16]. The theory put forward three independent variables: (1) Individual (Leader) Characteristics with a construct attitude towards change which describe the attitude of individual or leader to the introduction of IT innovation in an organization; (2) Internal Characteristics of an Organization has six constructs: (a) centralization- describe the degree to which power and control is put in the hand of an individual relative to others in the organization, it is discovered to have negative influence on the organizational innovativeness, (b) Complexity- is the degree to which members of an organization have high level of knowledge, expertise, specialties, and formal training, complexity was positively associated with organizational innovativeness (c) Formalization is the extent to which rules and procedures governed the roles of members of the organization, it has a negative influence on organizational innovativeness (d) Interconnectedness is the extent to which units in the organization are connected by interpersonal network for the exchange of new ideas or knowledge among members of the organization. It is positively related to the organizational innovativeness, (e) Organizational Slack it is degree to which additional resources are made available to the organization, it has a positive association with the organizational innovativeness, (f) Size is positively related to the organizational innovativeness, a large organization tend to be more innovative when compared with small organization. 
(3) External Characteristics of the Organization has a construct System Openness which is positively related to the organizational innovativeness. The construct describe the extent to which the organizations system is understood externally by others. However, empirical studies reveled that when DOI is applied to organizational level, inconsistency normally occurs due to failure to recognize the differences in unit of analysis, environment, and technology characteristics or they cannot predict the adoption of complex IT systems [22].

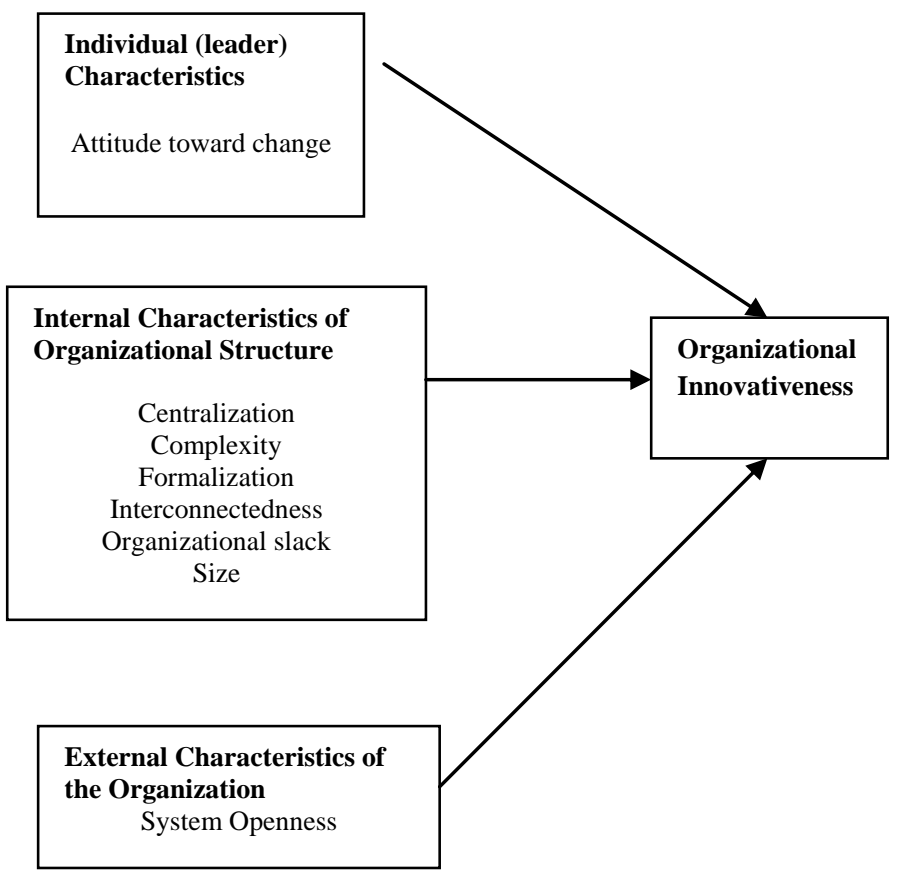

Figure 1. Diffusion of Innovation [12]. Source [10].

\subsection{Technology-Organization-Environment (TOE) Framework}

The TOE framework was developed in 1990 [16]. It identifies three features of an enterprise's context that affect series of steps taken to adopts and implements a technological innovation: technological context, organizational context, and environmental context (Figure 2). The TOE framework asses an organization's decision to implement an innovation depending on (a) the technologies appropriate to the organization; ( b) organizational attributes (i.e. company size, resources available, quality of human resources); and (c) environmental factors- business environment of the organization [19]. The TOE framework provides a useful analytical framework that can be used for studying the adoption and full understanding of different types of IT innovation. The TOE framework has a solid theoretical basis, unchanging empirical support, and the capability of application to IS innovation domains, though specific factors identified within the three contexts may vary across different studies [14].

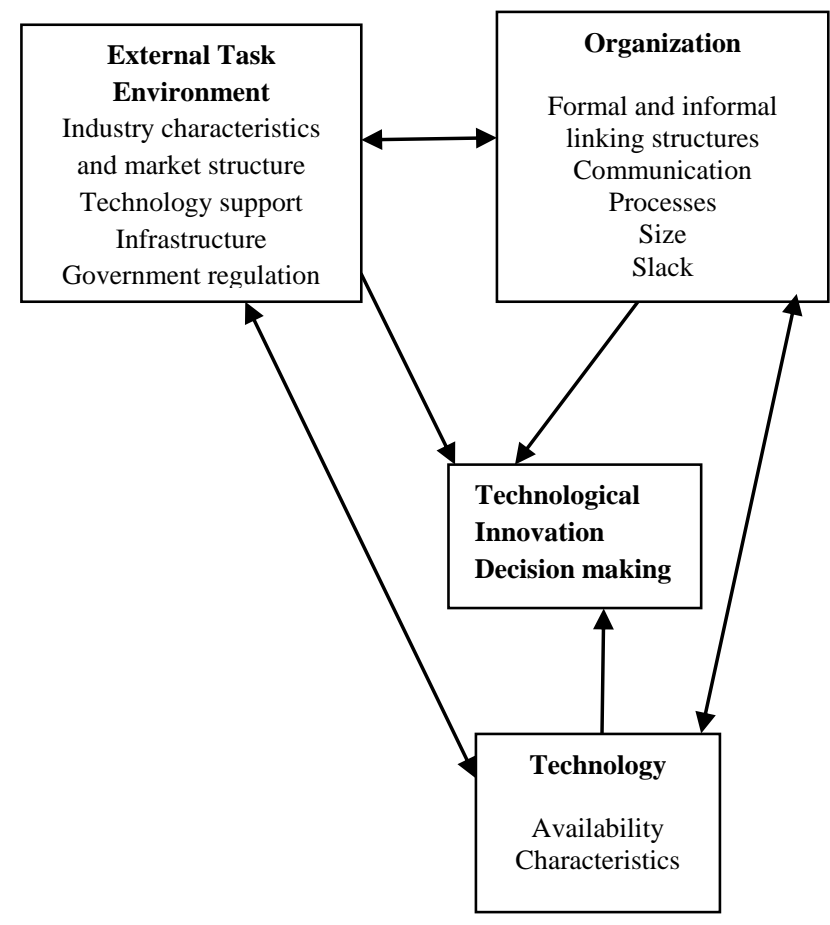

Figure 2: Technology, Organization, and Environment Framework [15]. Source [10].

\subsection{Iacovou et al. (1995) Model}

Iacovou et al. [10] analyzed inter-organizational systems (IOSs) characteristics that have capacity to effect organizations to adopt IT innovations in the context of Electronic Data Interchange (EDI) adoption (see figure 2.6). Their framework is appropriate for the purpose of explaining the adoption of an Interorganizational Systems (IOSs) [14]. It consists of three factors: (1) Perceived Benefits, describe the level of relative advantage that technology can provide an organization. It establish two major construct- direct benefits and indirect benefits, the two constructs is found to be positively associated with adoption, integration, and impact (dependent variables). (2) Organizational Readiness defined two constructs: (a) Financial resources obtained to pay for the installation, implementation of enhancement that follows and expenses of usage of EDI, (b) Technological readiness in terms of levels of IT usage and management in an organization. They are found to be positively related to the dependent variables. (3) External Pressure as a factor that has effect on the organization environment. It consist of two constructs: (a) Competitive pressure which measures the level of EDI capability of the organization in relation to that of its competitors in the same industry, (b) Imposition by trading partner refers to the potentials of a larger organization imposition on small organization in interorganizational relationships. The two construct were found to be positively related to the adoption of EDI. As part of future research, the authors suggested the inclusion of the model constructs in other studies to better determine the effect of each factors in an adoption study, the model can also be replicated to a larger organization in other to enlarge its generalizability [10]. 


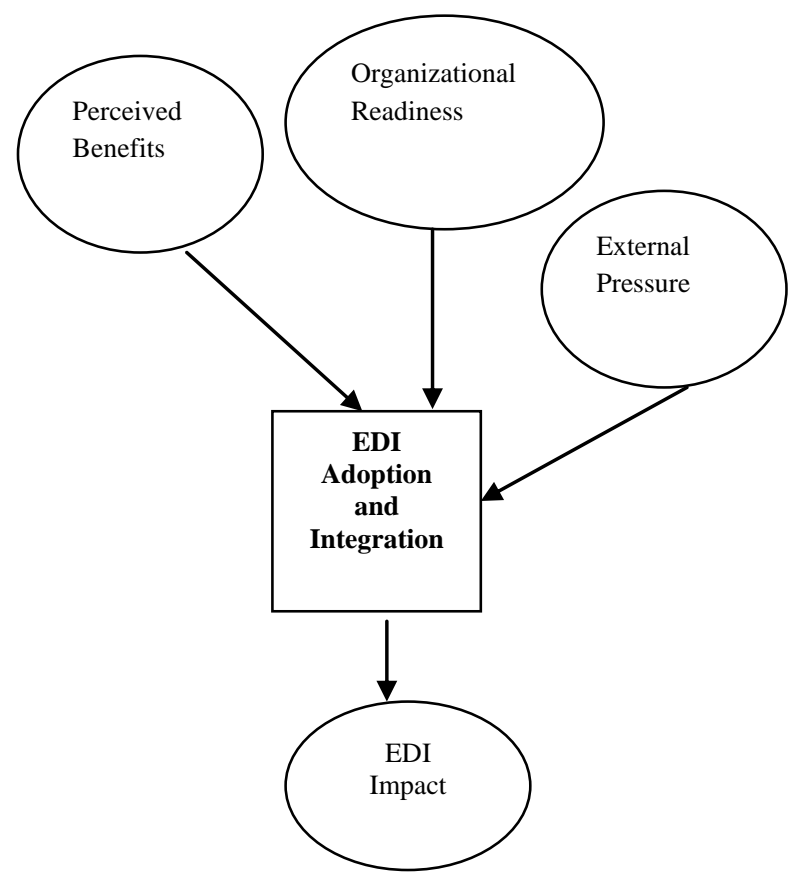

Figure 3: Iacovou et al. model. Source [7].

\section{THEORETICAL FRAMEWORK}

The need to understand the adoption of IT innovations factors in the organizational context has witnessed the development of theories on the subject matter ([20], [16], [10]). Research findings equally shows that combining related factors and integrating constructs of similar or same factors for a certain adoption study from these theories to develop a conceptual model assist in better understanding of the determinants factors influencing such adoption ( [22], [17], [14], [3]). In this research, factors and constructs from Diffusion of Innovations (DOI) proposed by [16], TechnologyOrganization-Environment (TOE) proposed by [20], and Iacovou et al., proposed by [10] were adapted and integrated to form the basis for our research model (See figure 4). However, modifications of some constructs were done to suit the peculiarity and complexity of the domain of our study. The relationships between the underpinning theories and the research variables are illustrated in Table 1 .

Table 1. Research constructs and source

\begin{tabular}{cll}
\hline $\begin{array}{l}\text { Serial } \\
\text { Number }\end{array}$ & Theories Used & $\begin{array}{l}\text { Research } \\
\text { Variable } \\
\text { Source }\end{array}$ \\
\hline $\mathbf{1}$ & $\begin{array}{l}\text { Diffusion of Innovation } \\
\text { (DOI) } \\
\text { (Rodgers, 1995) }\end{array}$ & $\begin{array}{l}\text { Technological } \\
\text { Readiness (TR) } \\
(\mathbf{2})\end{array}$ \\
$\mathbf{2}$ & $\begin{array}{l}\text { Technology-Organization- } \\
\text { Environment (TOE) } \\
\text { (Tornatzky \& Fleischer, } \\
\text { 1990) }\end{array}$ & $\begin{array}{l}\text { Organizational } \\
\text { Readiness (OR) } \\
(\mathbf{1 , 2 , 3})\end{array}$ \\
$\mathbf{3}$ & $\begin{array}{l}\text { Iacovou et al. } \\
\text { (Iacovou, Benbasat \& \& } \\
\text { Dexter, 1995) }\end{array}$ & $\begin{array}{l}\text { Perceived Benefits } \\
\text { (PB) }\end{array}$ \\
$\mathbf{4}$ & & $\begin{array}{l}\text { Environmental } \\
\text { Factors (EF) } \\
(\mathbf{2})\end{array}$ \\
\hline
\end{tabular}

The dependant variable is E-Voting adoption (EAD), which is the variable of interest in this research. We attempt to explain variance in this dependant variable by the four independent variables of (1) Technological Readiness (TR), Organizational Readiness (OR), (3) Environmental Factors (EF), and (4) Perceived Benefits (PB). TR is the degree to which the organization is ready technologically to adopt IT innovation, this is supported by TOE (1990) model. OR refers to the degree to which an organization is ready for the adoption of IT innovation in line with their internal structural characteristics, this variable is supported by [20], [16], and [10] models. EF identifies those factors external to the organization which can influence the successful adoption of the IT innovation; it is supported by TOE model. PB is the benefits derivable by organization for adopting an IT innovations, this can be direct or indirect in nature. This variable is supported by Iacovou et al., model.

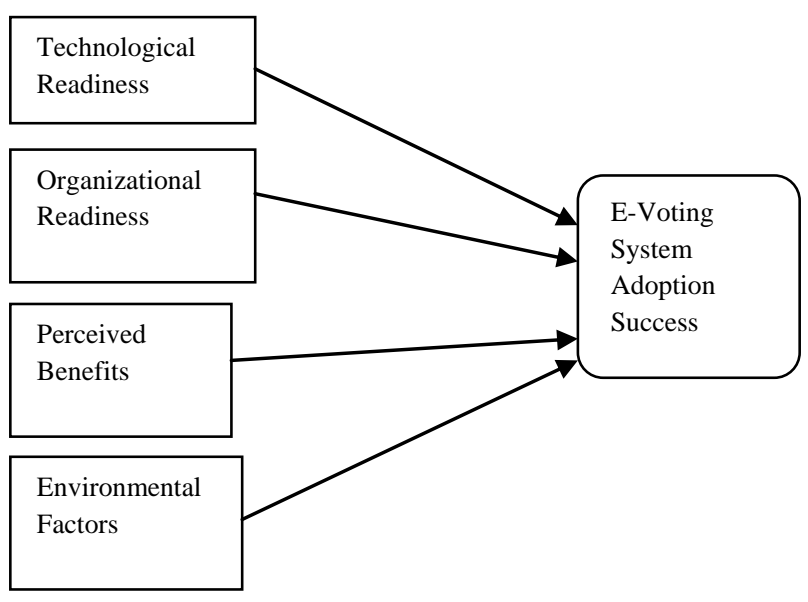

Figure 4: The Conceptual research Model

\section{RESEARCH CONSTRUCTS}

The proposed research model to be tested in this study is a combination of the joint predictive tendencies of three base models of DOI [16], TOE [20], and Iacovou et al., [10]. The four variables, TR, OR, $\mathrm{PB}$, and $\mathrm{EF}$ were derived from the three base model and are explained below.

\subsection{Technological Readiness (TR)}

This variable define the degree to which the organization is ready technologically to adopt IT innovation. Tornatzky and Fleischer (1990) describe technological factor (context) in terms of the availability and characteristics of the technologies (internal and external) relevant to the firm or organization. Findings of Oliveria and Martins (2011) confirm that, technological capacities among other factors played an important role in the IT diffusion process at organizational level. Alvar (2011) identify aspect of technology such as its reliability, its level of security and its relationship with existing technology contributing to the overall framework of factors of IT adoption. Technological factors is the most selfevident factors which an organization must establish and asses in relation to its present organizational structures and culture in order to make an explicit adoption decision of its readiness and ability with regard to happening in technology adoption [1]. Technological Readiness (TR) is expected to measure the technology metrics such as reliability, user ability, and 
security of E-Voting as a key determinant in the adoption process. The variable will also measure the readiness of INEC in term of technology resources such as hardware, software and other ICT equipments made available in order to achieve E-Voting adoption success.

\subsection{Organizational Readiness (OR)}

Organizational Readiness define the degree to which the organization is ready for IT innovation. Tornatzky and Fleischer (1990) describe organizational context (readiness) as the characteristics and resources of the organization, including the organization's size, degree of centralization, degree of formalization, managerial structure, human resources, amount of slack resources, and linkages among the employees. Rogers (1995) include interconnectedness as a significant construct to measure organizational determinant factors of IT adoption. Reviewed literatures on technology adoption establish organizational readiness as a crucial determinant factor to the successful adoption of an IT innovation. Molla and Licker (2005) confirm organizational factors especially human resources among other constructs as more influential than environment factors in adoption processes. Organizational readiness acts as a catalyst and a driving force to organization imitation to adopt a technology. Organizational readiness is positively correlated to the technology adoption [1]. The organizational readiness (OR) variables in the proposed research model is expected to measure Centralization, Compatibility, Public Education, Staff Attitude to change, Organizational slack, Interconnectedness, corporate governance, and Awareness.

\subsection{Environmental Factors (EF)}

Environmental Factors variable establish those factors external to the organization which can impact the successful adoption of IT innovation. The environmental context is the place in which an organization conducts its business. This includes the industry, competitors, regulations, and connections with the government. These are factors external to an organization that present limitations or restrictions and prospects for technological innovations ([6], [20]). Environmental Factors will operationalize five construct: (1) Organizational Independence; (2) Political Party Support; (3) Voters attitude; (4) Legal framework; (5) Government regulation.

\subsection{Perceived Benefits (PB)}

Perceived Benefits $(\mathrm{PB})$ variable describe the understanding of the benefits to be derived from adoption of IT innovation. A variable derived from [10] model. Perceived benefits refer to the expected advantages that IT adoption can provide to the organization. The benefits are both direct and indirect in nature. Direct benefits measure operational cost savings and other internal efficiencies arising from the IT adoption, while indirect benefits measure the opportunities that originate from the adoption of IT, such as a better service delivery and the capacity for process reengineering. At the level of the technology, the perceived benefits take into consideration the appropriate benefits of an IT adoption [8]. The research model is expected to measure indirect benefits of E-Voting technology to the organization under study in terms of, Accuracy of vote count, Stoppage of multiple registrations, and elimination of multiple voting, Ballot stuffing, Vote manipulation, and Ease of use.

\subsection{TESTING THE RELIABILITY AND VALIDITY OF THECONSTRUCTS}

A preliminary study was conducted between January and February 2012 among Independent National Electoral Commission (INEC) of Nigeria operational staff at the headquarters in Abuja and one of their state offices in Kwara State to investigate the perception of the staff of the commission about the organization intention to adopt EVoting systems and also to determine how their level of perception can aid the adoption success of E-Voting systems as an alternative methods of conducting acceptable elections in Nigeria.

Quantitative approach was used to capture data for the preliminary study. The questionnaire was built on a 5 point Likert scale, with 1 indicating Strongly Disagree and $\mathbf{5}$ indicating Strongly Agree. The questionnaire is divided into two main parts: (1) the demographic information which contains two questions. (2) Questions about factors that can predict INEC readiness to adopt and implement E-Voting system: Technological Readiness variable is made up of twenty-one (21) items; Organizational Readiness variable contains twenty (20) items; fifteen items was used for Perceived Benefits variable, while Environmental Factors variable consists of ten (10) items. Five (5) items was used to capture data for E-Voting Adoption variable construct. The validation of the construct was done through a computational method using SPSS 14.0

\subsection{Reliability of Research Constructs}

\subsubsection{Technological Readiness (TR)}

TR is a construct under this quantitative instrument (questionnaire) and it has twenty-one items whose reliability was measured with Cronbach's alpha $(\alpha)$. Items under this construct (dimension) are considered reliable with average Cronbach's alpha $(\alpha)$ of 0.817 which is greater than 0.7 [15] as shown in Table 2. and Figure 5.

\subsubsection{Organizational Readiness (OR)}

The readiness of the organization to adopt E-Voting Systems is a construct in this study with twenty items, the reliability of which was measured using Cronbach's alpha $(\alpha)$ with recorded value of 0.882. According to Sekaran (2000), items under a construct (dimension) with the average Cronbach's alpha $(\alpha)$ greater than 0.7 are reliable. Therefore, OR in this study with an average Cronbach's alpha is reliable as shown in Table 2 and Figure 5.

\subsubsection{Perceived Benefits (PB)}

The fifteen (15) items under this construct (dimension) are found to be reliable with the average Cronbach's alpha $(\alpha)$ of 0.767 which is greater than the benchmark of 0.7 ([18], [15], [9]) as shown in Table 2 and Figure 5.

\subsubsection{Environment Factors (EF)}

$\mathbf{E F}$, a construct under this study ten items whose reliability was measured with Cronbach's alpha $(\alpha)$ of 0.762 which is considered reliable ([19], [15]). See Table 2 and Figure 5.

\subsubsection{E-Voting Adoption (EAD)}

EAD is a construct under in this study with five items whose reliability was measured with Cronbach's alpha $(\alpha)$ as 0.853 . 
BI in this study is therefore reliable with an average Cronbach's alpha greater than 0.7 ([19], [15]). See Table 2 and Figure 5 while Table 3 shows the result of the factor analysis.

Table 2: Reliability Analysis for the Variables Construct

\begin{tabular}{lll}
\hline Variable & $\begin{array}{l}\text { Cronbach's } \\
\text { Alpha }(\boldsymbol{\alpha})\end{array}$ & No of Items \\
\hline TR & 0.817 & 21 \\
PB & 0.769 & 15 \\
OR & 0.882 & 20 \\
EF & 0.762 & 10 \\
EAD & 0.853 & 5 \\
\hline
\end{tabular}

\section{- Cronbach's Alpha $(\alpha) \quad$ No of Items}

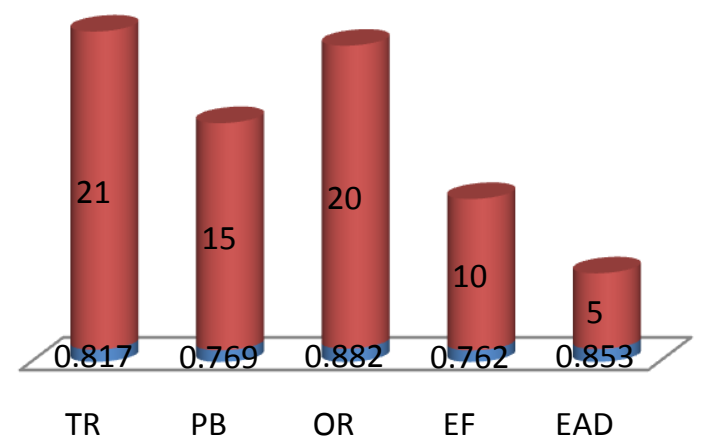

Figure 5: Chart Showing the Reliability Analysis for the variables constructs

\subsection{Validity of Instrument}

The collection of primary data during the preliminary study was to test whether the researcher can collect and analyzed data from participants (respondents) using the operationalized (questionnaires) items from the five constructs and to see if the researcher overall conceptual model design is workable. The 71 items questionnaire used for the preliminary study was subjected to principal component analysis (PCA) using SPSS version 14. Inspection of correlation matrix revealed the presence of many coefficients of .3 and above. PCA revealed five components with eigenvalues greater than 1 and explaining $15.7 \%, 15 \%, 14.8 \%, 7.3 \%$ and $5.6 \%$ of the variance respectively. An inspection of the Scree Plot revealed a clear break after the fifth components.

The five components solution explained a total of $58.3 \%$ of the variance, with component 1 contributing 15.7.\%, component $215 \%$, component $314.7 \%$, component $47.3 \%$ and component 5 with $5.60 \%$ respectively. To aid the interpretation of the five components, varimax rotation was performed. The rotated solution as presented in Table 3 below, revealed the presence of simple structure, with both components showing a number of strong loadings, and all variables loading substantially on only one component. The results of the analysis support the use of the items of the preliminary study as a separate scale for the final study. 
International Journal of Applied Information Systems (IJAIS) - ISSN : 2249-0868

Foundation of Computer Science FCS, New York, USA

Volume 5- No. 5, April 2013 - www.ijais.org

Table 3. Varimax Rotation of Five Factor Solution for Items Used in Preliminary Study

\begin{tabular}{|c|c|c|c|c|c|}
\hline \multirow[t]{2}{*}{ Items } & \multicolumn{3}{|c|}{ Component } & \multirow[b]{2}{*}{4} & \multirow[b]{2}{*}{5} \\
\hline & 1 & 2 & 3 & & \\
\hline EF4 & .718 & & & & \\
\hline EF3 & .656 & & & & \\
\hline EF5 & .595 & & & & \\
\hline EF8 & .576 & & & & \\
\hline $\mathrm{EF} 1$ & .572 & & & & \\
\hline TR7 & & .913 & & & \\
\hline TR9 & & .895 & & & \\
\hline TR20 & & .890 & & & \\
\hline TR19 & & .829 & & & \\
\hline TR8 & & .818 & & & \\
\hline TR10 & & .808 & & & \\
\hline TR12 & & .752 & & & \\
\hline TR14 & & .722 & & & \\
\hline TR21 & & .666 & & & \\
\hline TR17 & & .587 & & & \\
\hline TR16 & & .571 & & & \\
\hline TR3 & & .529 & & & \\
\hline TR1 & & .504 & & & \\
\hline OR16 & & & .790 & & \\
\hline OR7 & & & .756 & & \\
\hline OR6 & & & .722 & & \\
\hline OR5 & & & .695 & & \\
\hline OR2 & & & .694 & & \\
\hline OR15 & & & .691 & & \\
\hline OR11 & & & .687 & & \\
\hline OR9 & & & .669 & & \\
\hline OR13 & & & .631 & & \\
\hline OR12 & & & .611 & & \\
\hline OR18 & & & .583 & & \\
\hline OR8 & & & .578 & & \\
\hline OR10 & & & .575 & & \\
\hline PB4 & & & & .679 & \\
\hline PB9 & & & & .640 & \\
\hline PB5 & & & & .578 & \\
\hline PB11 & & & & .576 & \\
\hline PB14 & & & & .559 & \\
\hline PB3 & & & & .527 & \\
\hline EAD2 & & & & & .765 \\
\hline EAD4 & & & & & .659 \\
\hline EAD3 & & & & & .610 \\
\hline EAD1 & & & & & .542 \\
\hline
\end{tabular}

(Only loadings above .5 are display) 


\section{CONCLUSION}

The resulted conceptual framework is to be adopted in this study as it is validated with both the result of reliability analysis and factor analysis proving to be acceptable. It is evidenced that the model can predict acceptance of e-voting system at organizational level using Nigerian Independent Electoral Commission as the case study.

\section{REFERENCES}

[1] Alvar, N. 2011. Technology Adoption Decision Framework. Master Thesis, The College of St. Scholastica, Duluth, Minnesota, USA.

[2] Aroge, S. T. 2012. Civic Education as a Panacea to Electoral Malpractices in Nigeria. Business and Management Research, 1(1). 141 - 146.

[3] Awa, O.H., Ukoha, O., Emecheta, C.B., and Nzogwu, S.2012. Integrating TAM and TOE frameworks and Expanding their Characteristics Cinstructs for ECommerce Adoption by SMEs. Proceedings of informing science \& IT Education Conference (InSITE), Montreal, Canada. Retrieved from http://www.Proceedings.informingscience.org/InSITE/20 12Proceedings.pdf.

[4] Ayo, C., Adeniyi, A., \& Fatudimu, I. 2008. EDemocracy: A requirement for a successful E-Voting and E-Government implementation in Nigeria. International Journal of natural and Applied Sciences, $4(3), 310-318$.

[5] Caarls, S. 2010. E-Voting Handbook: A key steps in the implementation of e-enabled elections. Councils of Europe Publishing, F-67075 Strasbourg Cedex. Retrieved from http://book.coe.int

[6] Chau, P.Y.K \& Tam, K.Y. 1997. Factors affecting the adoption of open systems: an exploratory study, MIS Quarterly, 21 (1), 1-24.

[7] Chong, Y.A., Ooi, K., \& Raman, M.B. 2009. Factors affecting the adoption level of e-commerce: an empirical study, Journal of Computer Information Systems, 13-22.

[8] Chwelos, P., Benbasat, I. and Dexter, A.S. 2001. Research Report: Empirical Test of an EDI Adoption Model. Information Systems Research, 1-33.

[9] Ezegwu, C. 2006. Problems and prospects of adopting electronic voting systems in Nigeria. Conference of the Nigerian Political Science Association (NPSA), South East Chapter, Namidi Azikiwe University, Nigeria.

[10] Iacovou, C.L., Benbasat, I. and Dexter, A.S. 1995. Electronic Data Interchange and small Organizations:
Inplementation Science, 3: 41Adoption and Impact of Technology, MIS Quarterly, 19(4), 465 - 485.

[11] Molla, A. \& Licker, P. S. 2005. eCommerce adoption in developing countries: a model and instrument, Information \& Management, 42, 877 - 899.

[12] Okoye, F. 2010. Nigeria: Civil Society and Electronic Voting Systems, the Challenges. Vanguard, January 14.

[13] Olakunke, A. O. 2003. Research Methods in Social Sciences. (Second Edition), E-Book Press, Norway.

[14] Oliveira, T. \& Martins, M. 2011. Literature Review of Information Technology Adoption Models at Firm Level [electronic version]. The Electronic Journal Information Systems Evaluation. 14(1), 110 - 121.

[15] Pallant, J. 2003. A step by Step guide to data analysis using SPSS. Open University Press, McGraw- Hill Education, Philadelphia, USA.

[16] Rorgers, E. M. 1995. Diffusion of Innovations, Fourth Edition ed., New York, Free Press.

[17] Scott, D.S., Poltnikoff, C.R., Karunamuni, N., Bize, R., and Rodgers, W. 2008. Factors influencing the adoption of an innovation: An examination of the uptake of the Canadian Heart Health Kit (HHK). Implementation Science. Retrieved from http://www.implementation_science.com/content/3/141

[18] Sekaran, U. 2000. Research Methods for Business: A skill building approach. NYC: John Willey Sons, Inc.

[19] Sekaran, U. and Bougie, R. 2011. Research Methods for Business: A Skill Building Approach (Fifth Edition). NYC: John Willey Sons, Inc.

[20] Tornatzky, L. and Fleischer, M. 1990. The Process of Technology Innovation, Lexington, MA, Lexington Books.

[21] Villafiorita, A., Weldemariam, K. \& Tiella, R. 2009. Development, formal verification, and evaluation of an E-voting system with VVPAT. IEEE Transactions on Information and Security, 4(4), 651 - 661.

[22] Yi, Y.M., Jackson, D.J., Park, S.J., and Probst, C.J. 2006. Understanding information technology acceptance by individual professionals: Toward an integrative view. Information \& Management 43, 350 - 363. Retrieved from http://www.sciencedirect.com

[23] Zhu, K., Dong, S., Xu, X. S., and Kraemer, L., K. 2006. Innovation diffusion in global contexts: determinants of post-adoption digital transformation of European companies, European Journal of Information Systems, $15,601-616$. 